\title{
Coupled effects of biochar use and farming practice on physical properties of a salt-affected soil with wheat-maize rotation
}

\author{
Liang Xiao ${ }^{1,2} \cdot$ Guodong Yuan ${ }^{3}(1) \cdot$ Lirong Feng $^{1,2} \cdot$ Dongxue Bi ${ }^{1,2} \cdot$ Jing Wei $^{1} \cdot$ Guanhua Shen $^{3} \cdot$ Zhaohui Liu $^{4}$
}

Received: 28 July 2019 / Accepted: 31 March 2020

(C) Springer-Verlag GmbH Germany, part of Springer Nature 2020

\begin{abstract}
Purpose Being carbon-rich and porous, biochar has the potential to improve soil physical properties, so does conventional farming practice. Here, a field trial was conducted to investigate the combined effects of biochar use and farming practice on the physical properties of a salt-affected compact soil for wheat-maize rotation in the Yellow River Delta region.

Materials and methods Salix fragilis L. was used as feedstock to produce biochar in the field via aerobic carbonization at an average temperature of $502{ }^{\circ} \mathrm{C}$, terminated by a water mist spray, for use as a soil amendment at $0,1,2$, and $4 \mathrm{~g} \mathrm{~kg}^{-1}$ doses (CK, $\mathrm{T} 1, \mathrm{~T} 2$, and T3, respectively). Farming practices included rotary tillage/straw returning for wheat sowing, spring irrigation, notillage seeding of maize, and autumn irrigation. Both cutting ring and composite samples of the soil were collected at four stages of wheat-maize rotation $(22,238,321$, and $382 \mathrm{~d}$ after the benchmark date of land preparation for wheat sowing) for the determination of soil properties by established methods.

Results and discussion Rotary tillage/straw returning reduced soil bulk density (BD) from 1.48 to $1.27 \mathrm{~g} \mathrm{~cm}^{-3}$ (CK) and $1.14 \mathrm{~g} \mathrm{~cm}^{-3}$ (T3) and increased saturated hydraulic conductivity $(K s)$ from $0.05 \times 10^{-5}$ to $0.75 \times 10^{-5} \mathrm{~cm} \mathrm{~s}^{-1}$ (CK) and $1.25 \times 10^{-5} \mathrm{~cm} \mathrm{~s}^{-1}$ (T3). This tillage effect on BD and $K s$ gradually disappeared due to the disturbance from the subsequent farming practice. Biochar use lessened the disturbance. At maize harvest, BD was 1.47 (CK) vs. $1.34 \mathrm{~g} \mathrm{~cm}^{-3}$ (T3), and $K s$ was $0.06 \times 10^{-5}(\mathrm{CK})$ vs. $0.28 \times 10^{-5} \mathrm{~cm} \mathrm{~s}^{-1}$ (T3); in comparison with CK, T3 increased $\mathrm{Na}^{+}$leaching by $65 \%, \mathrm{Cl}^{-}$leaching by $98 \%$, organic carbon content by $40.3 \%$, and water-stable aggregates $(0.25-2 \mathrm{~mm})$ by $38 \%$, indicating an improvement in soil properties.

Conclusions Biochar use and rotary tillage improved soil physical properties $(\mathrm{BD}, K \mathrm{~s})$ and favored soil aeration, water filtration, and salt leaching, which further helped the accumulation of soil organic carbon, the formation of water-stable aggregates, and the amelioration of salt-affected compact soil.
\end{abstract}

Keywords Bulk density $\cdot$ Saturated hydraulic conductivity $\cdot$ Salt leaching $\cdot$ Organic carbon $\cdot$ Water-stable aggregates $\cdot$ Biochar

Responsible editor: Yong Sik Ok

Guodong Yuan

yuanguodong@zqu.edu.cn

1 Yantai Institute of Coastal Zone Research, Chinese Academy of Sciences, Yantai 264003, Shandong, China

2 University of Chinese Academy of Sciences, Beijing 100049, China

3 Guangdong Provincial Key Laboratory of Environmental Health and Land Resource, Zhaoqing University,

Zhaoqing 526061, Guangdong, China

4 Shandong Academy of Agricultural Sciences, Jinan 250000, Shandong, China

\section{Introduction}

Soils in the Yellow River Delta region are typically compact (Zhang et al. 2015), with excessive soluble salts and exchangeable $\mathrm{Na}^{+}$, resulting in low productivity (Luo et al. 2017). Rotary tillage with straw returning was reported to improve soil structure in this area (Xie et al. 2017). This beneficial effect, however, was short-lived. After irrigation and straw decomposition, the soil gradually became compact again. It remains a challenge to mitigate the compaction of coastal saline soil in the region cost-effectively.

Biochar is a versatile material for environmental and agricultural applications (Wei et al. 2019a, b, c). Its use as a soil 
amendment could improve soil porosity, $K \mathrm{~s}$, and water infiltration (Ajayi et al. 2016); alleviate soil compaction (Lehmann and Joseph 2009); reduce salt content (Al-Wabel et al. 2018); increase soil carbon (Xu et al. 2018); and enhance soil aggregation (Saifullah et al. 2018). The effects of biochar attributes, namely the particle size (Sun et al. 2018), pore size (Liu et al. 2017), and dosage, on soil properties were assessed in laboratory studies or field trials for different soils (Khademalrasoul et al. 2014). The large specific surface area and irregular porous structure of biochar (Ibrahim et al. 2016; Liu et al. 2017) reduced soil bulk density (BD) (Blancocanqui 2017), increased soil porosity (Obia et al. 2016), and enhanced saturated hydraulic conductivity of sandy or compact soils (Ouyang et al. 2013), particularly when biochar particle size was less than $1 \mathrm{~mm}$ (Sun et al. 2018). Alghamdi (2018) suggested a proper dosage of biochar at $0.5-4 \%$ for improving soil physical properties. Omondi et al. (2016) reported a reduction in soil BD by an average of $12 \%$ as a result of biochar use. The irregular and fluffy structure of biochar contributed to the reduction in BD (Blancocanqui 2017) and the increase in saturated hydraulic conductivity (Liu et al. 2016). As a source of nutrients, biochar could improve soil microenvironment and enhance its microbial activity (Dong et al. 2016). Further, the secretions of organic compounds from microbes could accelerate the formation of soil aggregates (Burrell et al. 2016). All the above processes and factors could contribute to better soil physical conditions (Pietikäinen et al. 2000; Six et al. 2004; Downie et al. 2009).

Despite the reported benefits, biochar use as a soil amendment is constrained by high cost (Simon et al. 2011; Shabangu et al. 2014). Even at a $1 \%$ dose (ca. 15 tons of biochar/ha) and a low price of $\$ 222 /$ ton (Shackley et al. 2011), the cost would be prohibitive to crop production. Besides, limited effort has been made to assess the longevity of biochar effect on soil physical properties via field trials (Saifullah et al. 2018), let alone the combined effect of biochar use and farming operations (e.g., straw return, rotary tillage, irrigation) that have long been in practice (Herath et al. 2013; Alghamdi 2018).

To remove the cost barrier, we used biowaste of Salix fragilis L. to produce low-cost biochar $(\$ 24 /$ ton) in the field via aerobic carbonization (Xiao et al. 2019a) by mimicking the natural charring processes of thunder inducing forest fire and rain terminating combustion, as detailed in Section 2.2. The biochar was then used as a soil amendment at small doses $\left(0,1,2\right.$, and $\left.4 \mathrm{~g} \mathrm{~kg}^{-1}\right)$ in a field trial to reveal the effect and longevity of biochar and farming operations on the physical properties of a salt-affected soil with wheat-maize rotation. This work differs from other studies in that (1) biochar was produced from local biowaste in the field for use in the same place, thus eliminating transportation and storage cost; and (2) the longevity of biochar effect on soil physical properties was assessed together with the conventional farming operations in the Yellow River Delta, making the outcome from this research applicable to local soil management.

\section{Materials and methods}

\subsection{Study area}

The field trial site of $67.5 \mathrm{~m}$ long and $49.0 \mathrm{~m}$ wide, located in Xianhe Town, Hekou District, Dongying City $\left(37^{\circ} 55.30^{\prime}, 118^{\circ} 48.88^{\prime}\right)$, was farmland with irrigation and drainage system in place. The soils in this region are typically stratified with a sandy loam layer on the top, a sand layer in the middle, and a red earth layer on the bottom, with a compact structure (Zhang et al. 2011). Cotton was planted at the beginning of the land reclamation (in the 1990s), followed by wheat-maize rotation since 2014 . This rotation has been accompanied by the return of crop straw to the soil. Wheat (Triticum aestivum L.) was sowed in early winter with rotary tillage and maize (Zea mays L.) by no-tillage seeding in summer.

\subsection{Biochar production and field trial}

Biowaste of the local Salix fragilis L. was used to produce biochar in the field through an aerobic carbonization process via a coupled fire-water method (Xiao et al. 2019a, 2019b). The carbonization process had the dual features of the combustion on the surface of biomass and the oxygen-limiting pyrolysis inside of the biomass. Briefly, Salix fragilis L. branches were ignited at one direction of a brick-constructed trough for aerobic carbonization at an average temperature of $502{ }^{\circ} \mathrm{C}$, followed by a water mist spray to dark red char at 0 min exposure time for the termination of the carbonization and the formation of biochar. Operating parameters that control the properties of biochar in conventional pyrolysis (AlWabel et al. 2018), namely the heating rate, pyrolysis temperature, and residence time, were simplified to a single one in aerobic carbonization: exposure time, i.e., the time between a burning char fell to the ground and water spray was applied to terminate the pyrolysis (Xiao et al. 2019b). The properties of biochar were determined by established methods, as described in Section 2.3.

The formed biochar was crushed to less than $1 \mathrm{~mm}$ and then mixed with the topsoil $(0-20 \mathrm{~cm})$ in the filed by rotary tillage (twice). Each plot in the field trial was $10 \times 2 \mathrm{~m}^{2}$, with 4 replicates. Plots were randomly arranged, with an isolation gap of $0.5 \mathrm{~m}$ wide between them. Treatments included control (CK), and 1, 2, and $4 \mathrm{~g} \mathrm{~kg}^{-1}$ of biochar doses (labeled as $\mathrm{T} 1$, $\mathrm{T} 2, \mathrm{~T} 3$, respectively). 
Table 1 Physical and chemical properties of the salt-affected soil

\begin{tabular}{llllllll}
\hline Horizon & $\begin{array}{l}\text { Depth } \\
(\mathrm{cm})\end{array}$ & $\begin{array}{l}\text { Bulk density } \\
\left(\mathrm{g} \mathrm{cm}^{-3}\right)\end{array}$ & $\begin{array}{l}\text { Capillary } \\
\text { porosity }(\%)\end{array}$ & $\begin{array}{l}K \mathrm{~s} \\
\left(\times 10^{-5} \mathrm{~cm} \mathrm{~s}^{-1}\right)\end{array}$ & $\mathrm{pH}$ & $\begin{array}{l}\mathrm{EC} \\
\left(\mathrm{mS} \mathrm{cm}^{-1}\right)\end{array}$ & $\begin{array}{l}\text { Salt content }(\% o) \\
\text { Organic } \\
\left.\text { carbon }(\mathrm{g} \mathrm{kg})^{-1}\right)\end{array}$ \\
\hline Sandy loam & $0-15$ & $1.48 \pm 0.05$ & $29.5 \pm 2.50$ & $0.05 \pm 0.00$ & $8.15 \pm 0.23$ & $1.32 \pm 0.11$ & $2.80 \pm 0.13$ \\
\hline
\end{tabular}

$K s$, saturated hydraulic conductivity; $E C$ electrical conductivity

\subsection{Soil sample collection and analysis}

Soil samples were collected from the topsoil layer $(0$ $15 \mathrm{~cm}$ ) by the five-point sampling of $\mathrm{S}$ route in each plot. Both cutting ring and mixed samples were collected on 25 September 2017 (as benchmark date), at stage 1 (22 days after the benchmark, after the completion of biochar and maize straw mixing with soil via rotary tillage for wheat sowing), at stage 2 (238 days after benchmark, after spring irrigation), at stage 3 (321 days after benchmark, after no-till seeding of maize), and at stage 4 (382 days after benchmark, after autumn irrigation).

The BD, capillary porosity (CP), and filed capacity of the salt-affected soil were determined by the cutting ring method (Lu 1999; Shao et al. 2006), and saturated hydraulic conductivity by constant water head test (Herath et al. 2013). Waterstable aggregates (WSA) $(0.25-0.5 \mathrm{~mm}, 0.5-1 \mathrm{~mm}, 1-2 \mathrm{~mm})$ were determined by the wet sieve method by an aggregate analyzer (TTF-100, Zhejiang Xiaolong) (Elliott 1986). Composite soil samples were analyzed for salt content by the weighing method (Bao 2000) and organic carbon by wet oxidation using $\mathrm{K}_{2} \mathrm{Cr}_{2} \mathrm{O}_{7}-\mathrm{H}_{2} \mathrm{SO}_{4}$ ( $\mathrm{Lu}$ 1999). The $\mathrm{pH}$ and electric conductivity (EC) of the biochar and soil were measured in a suspension at a sample: water ratio of 1:5 (w/v) after shaking at $160 \mathrm{r} \mathrm{min}^{-1}$ for $24 \mathrm{~h}$, using a $\mathrm{pH}$ meter (Five Easy Plus, METTLER TOLEDO) and a conductivity meter (DDS-11A), respectively. Cations and anions in the soil extracts (soil: water ratio of $1: 5 \mathrm{w} / \mathrm{v}$ ) were measured by ion chromatography (ICS3000, Dionex) (Chaganti et al. 2015). Biochar was analyzed for its ash content by heating in a muffle furnace at $800{ }^{\circ} \mathrm{C}$ for $4 \mathrm{~h}$, and for elemental compositions using an elemental analyzer (Vario Micro cube, Elementar, Germany) (Xiao et al. 2019b). The concentration of acidic functional groups in biochar was determined by the titration method (the International Humic Substances Society 2019). The biochar was observed for its morphological features by a scanning electron microscope (Hitachi S-4800, Japan) and determined for its specific surface area by sorption of $\mathrm{N}_{2}$ at $77 \mathrm{~K}$, using a Quantachrome Autosorb-iQ analyzer, and applying the Brunauer-Emmett-Teller (BET) equation (Herath et al. 2013; Xiao et al. 2019b).

\subsection{Statistical analysis}

Excel 2013, SPSS 16.0, and Origin 8.0 were used for calculation, data analysis, and figure drawing. One-way ANOVA was performed for statistical significance analysis (Duncan's test, $p<0.05$ ).

\section{Results}

\subsection{Basic properties of soil and biochar}

The soil had a high BD, low saturated hydraulic conductivity, alkaline $\mathrm{pH}$, and low organic carbon content (Table 1). They are typical for salt-affected soils in the region.

As shown in Table 2 and Fig. 1, the biochar used in the field trial had an alkaline $\mathrm{pH}$, a moderate ash content, a high carbon content, and a porous structure. With abundant oxygencontaining functional groups (carboxyl and phenolichydroxyl) and a large specific surface area $\left(271.68 \mathrm{~m}^{2} \mathrm{~g}^{-1}\right)$, the biochar would be a suitable adsorbent for cations.

\subsection{Soil bulk density}

As shown in Fig. 2, with an increase in biochar dosage, BD followed a declining trend at each sampling stage. A dosage of $4 \mathrm{~g} \mathrm{~kg}^{-1}$ was sufficient to make a significant difference to CK in BD. With the lapse of time, the magnitude of difference in $\mathrm{BD}$ among treatments gradually decreased. For example, at $4 \mathrm{~g} \mathrm{~kg}^{-1}$ dosage, BD decreased by $11.3 \%$, from 1.42 in CK to

Table 2 Physical properties, elemental compositions, surface functional groups, and specific surface area of biochar

\begin{tabular}{llllllllll}
\hline $\mathrm{pH}$ & $\begin{array}{l}\mathrm{EC} \\
\left(\mathrm{mS} \mathrm{cm}{ }^{-1}\right)\end{array}$ & $\begin{array}{l}\text { Ash } \\
(\%)\end{array}$ & $\mathrm{C}$ & $\mathrm{N}$ & $\mathrm{H}$ & $\mathrm{S}$ & $\begin{array}{l}-\mathrm{COOH} \\
\left(\mathrm{mol} \mathrm{kg}^{-1}\right)\end{array}$ & $\begin{array}{l}-\mathrm{OH} \\
\left(\mathrm{m}^{2} \mathrm{~g}^{-1}\right)\end{array}$ \\
\hline $9.62 \pm 0.02$ & $4.93 \pm 0.05$ & $24.15 \pm 1.41$ & $60.30 \pm 0.01$ & $0.52 \pm 0.01$ & $1.87 \pm 0.01$ & $0.02 \pm 0.01$ & $0.98 \pm 0.01$ & $0.59 \pm 0.04$ & $271.68 \pm 12.57$ \\
\hline
\end{tabular}

$E C$, electrical conductivity; SSA, specific surface area 


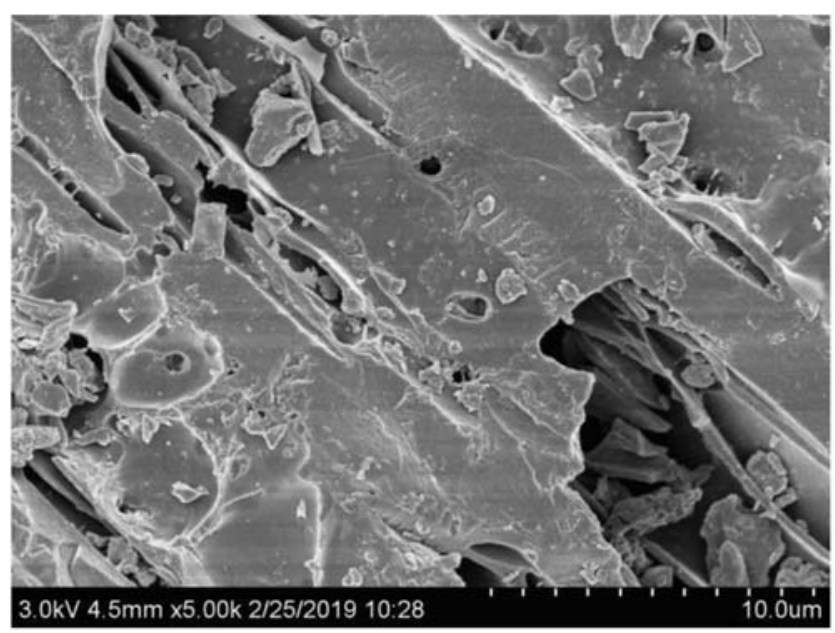

Fig. 1 Scanning electron microscopic image of biochar

$1.26 \mathrm{~g} \mathrm{~cm}^{-3}$ in $\mathrm{T} 3$ at stage 3, whereas the corresponding decrease at stage 4 was $8.8 \%$. The beneficial effect of biochar in reducing $\mathrm{BD}$, however, disappeared over time with the disturbance from the subsequent farming practice. The $\mathrm{BD}$ of $\mathrm{T} 3$, for example, changed from 1.14 at stages $1-2$ to 1.26 at stage 3 and $1.34 \mathrm{~g} \mathrm{~cm}^{-3}$ at stage 4 , accompanied by a decline in standard deviation $(0.09,0.11,0.09$, and 0.01 at stages $1-4$, respectively), which indicated the effects of farming practice on $\mathrm{BD}$ were gradually stabilized. In comparison with the benchmark BD of $1.48 \mathrm{~g} \mathrm{~cm}^{-3}$, it can be concluded that biochar application reduced $\mathrm{BD}$ at all stages during the wheatmaize rotation.

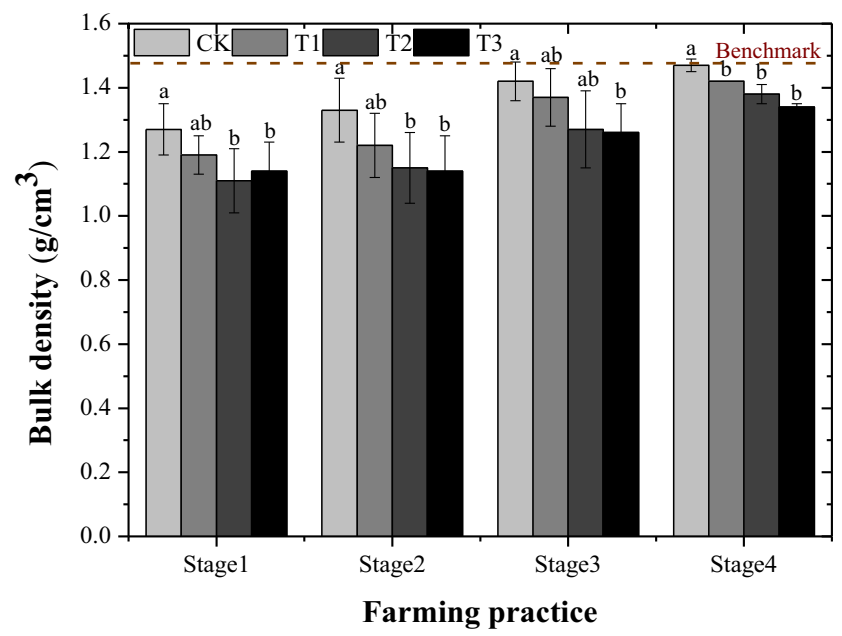

Fig. 2 Effects of biochar use on soil bulk density, as modulated by farming practice. Stage 1, after rotary tillage with straw returning for wheat sowing; Stage 2, after spring irrigation; Stage 3, after no-till seeding of maize; and Stage 4: after autumn irrigation. CK, saline soil without biochar use; T1-T3, biochar-amended saline soil (at the dose of $1,2,4 \mathrm{~g} \mathrm{~kg}^{-1}$ ). Different lower-case letters at the same stage indicate significant differences between treatments ( $p<0.05$, Duncan's test)

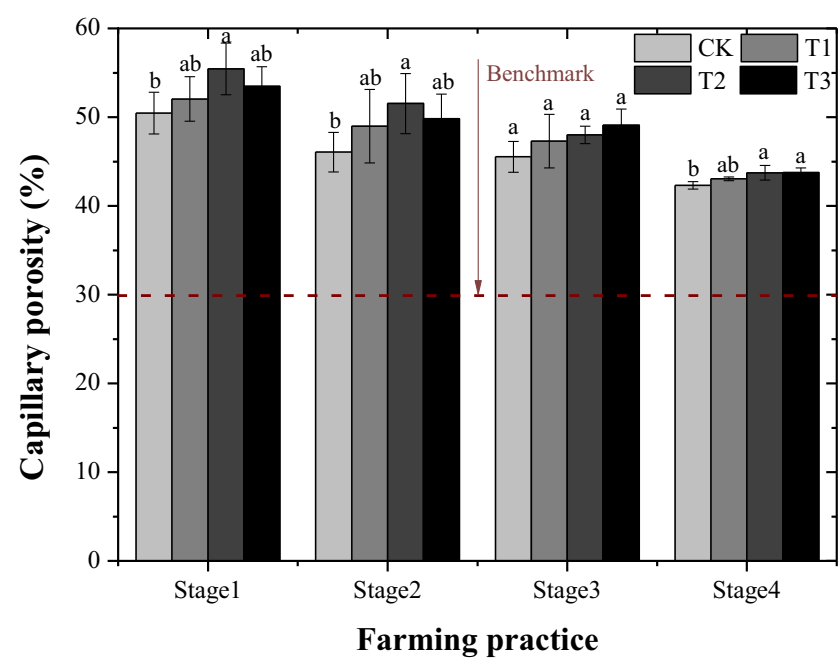

Fig. 3 The effects of biochar use on capillary porosity, as modulated by farming practice. Stages $1-4, \mathrm{CK}$, and T1-T3 are the same as noted in Fig. 2. Different lower-case letters at the same stage indicate significant differences between treatments ( $p<0.05$, Duncan's test)

\subsection{Capillary porosity}

In comparison with the benchmark $\mathrm{CP}$ before the field trial started, rotary tillage at stage 1 has dramatically increased CP (Fig. 3), which was further enhanced by biochar use. From stages 1 to 4 , the $\mathrm{CP}$ of each treatment decreased. At $\mathrm{T} 2$, for example, CP decreased from $55.4 \%$ to $51.5 \%, 48.0 \%$, and $43.7 \%$. Results demonstrated that farming operations such as tillage and irrigation had a controlling effect on $\mathrm{CP}$, and biochar use at $1-4 \mathrm{~g} \mathrm{~kg}^{-1}$ further increased it to produce an additive effect. From stages 1 to 4 , the variability of each treatment narrowed, suggesting the combined effect of farming practice and biochar use was stabilized. Rotary tillage quickly increased $\mathrm{CP}$ of the soil, and biochar application further

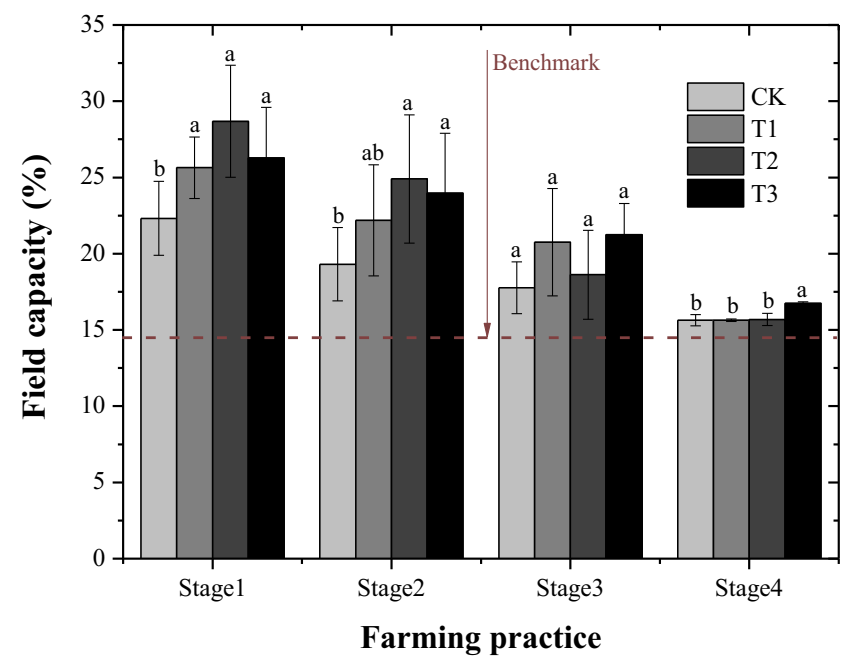

Fig. 4 Effects of biochar use on-field capacity, as modulated by farming practice. Stages 1-4, CK, and T1-T3 are the same as noted in Fig. 2. Different lower-case letters at the same stage indicate significant differences between treatments $(p<0.05$, Duncan's test) 


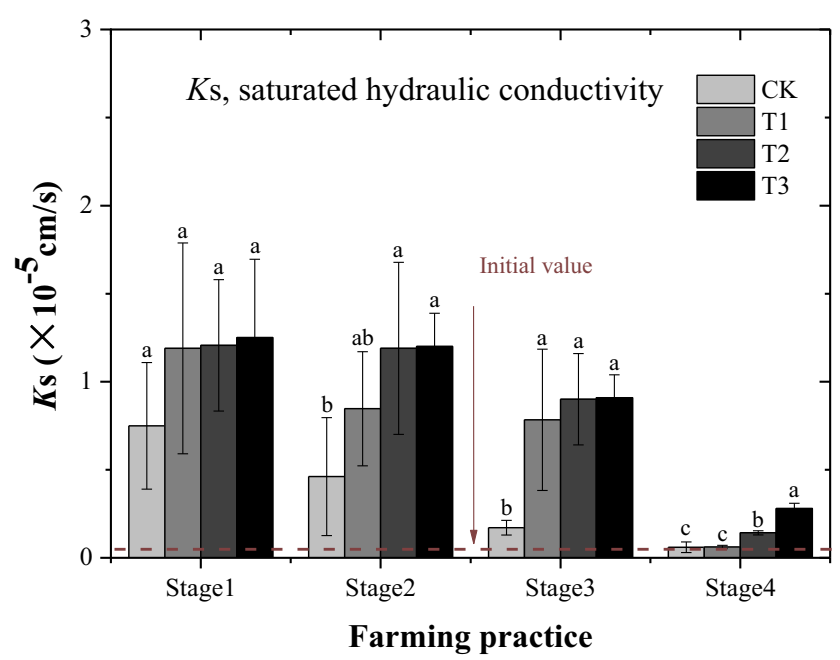

Fig. 5 Effects of biochar use on saturated hydraulic conductivity $(K \mathrm{~s})$, as modulated by farming practice. Stages $1-4, \mathrm{CK}$, and T1-T3 are the same as noted in Fig. 2. Different lower-case letters at the same stage indicate significant differences between treatments $(p<0.05$, Duncan's test)

enhanced the effect and helped stabilize it from the disturbance of subsequent irrigation and rainfall.

\subsection{Field capacity}

In comparison with the benchmark value, rotary tillage before wheat sowing (stage 1) loosed soil and thus increased its field capacity (FC) (Fig. 4). Though not a linear relationship, biochar application further increased FC by $13.0 \%, 22.2 \%$, and $15.1 \%$ at 1,2 , and $4 \mathrm{~g} \mathrm{~kg}^{-1}$ doses, respectively. Spring irrigation (stage 2) reduced FC in all treatments. This destructive process was further strengthened by maize sowing and autumn irrigation. By the time of maize harvest, the field capacities were close to the initial value before the field trial started, and only T3 (biochar dose of $4 \mathrm{~g} \mathrm{~kg}^{-1}$ ) kept an effect on FC (8.2\% higher than CK). Similar to BD and CP, the internal variability of $\mathrm{FC}$ for each treatment at stage 4 was smaller than those in stages 1-3, implying the combined effect of farming practice and biochar use became stabilized. Thus, in wheatmaize rotation, biochar use at $4 \mathrm{~g} \mathrm{~kg}^{-1}$ in combination with rotary tillage/straw returning at the beginning effectively increased FC and maintained this effect to the end of the cropping season.

\subsection{Saturated hydraulic conductivity (Ks)}

As shown in Fig. 5, biochar application increased $K$ s, and this trend was maintained during the wheat-maize cropping season, At $2 \mathrm{~g} \mathrm{~kg}^{-1}$ dose, for example, soil $\mathrm{Ks}$ was $33.0 \%, 61.0 \%$, $78.6 \%$, and $57.1 \%$ higher than CK at stages 1 to 4 , respectively. The corresponding increases at $4 \mathrm{~g} \mathrm{~kg}^{-1}$ dose were $40.0 \%$, $61.7 \%, 81.3 \%$, and $78.6 \%$, respectively. With the increasing disturbance from farming operations at stages 1 to 4 , the $K$ s of the soil gradually decreased from $1.21 \times 10^{-5}$ to $1.18 \times 10^{-5}$, $0.90 \times 10^{-5}$, and $0.14 \times 10^{-5} \mathrm{~cm} \mathrm{~s}^{-1}$ at $2 \mathrm{~g} \mathrm{~kg}^{-1}$ biochar dose, and from $1.25 \times 10^{-5}$ to $1.20 \times 10^{-5}, 0.91 \times 10^{-5}$, and $0.28 \times$ $10^{-5} \mathrm{~cm} \mathrm{~s}^{-1}$ at $4 \mathrm{~g} \mathrm{~kg}^{-1}$ dose. This decrease was accompanied by reduced variability of $K \mathrm{~s}$ among treatments. Rotary tillage before wheat sowing greatly increased $K \mathrm{~s}$, and biochar use enhanced this increase and helped resist the disturbing effect of the subsequent farming operations on $K \mathrm{~s}$.
Fig. 6 Biochar amendment reduced soil salt content at stage 2 (after spring irrigation) and stage 4 (after autumn irrigation). CK and $\mathrm{T} 1-\mathrm{T} 3$ are the same as noted in Fig. 2. Different lower-case letters at the same stage indicate significant differences between treatments $(p<0.05$, Duncan's test)
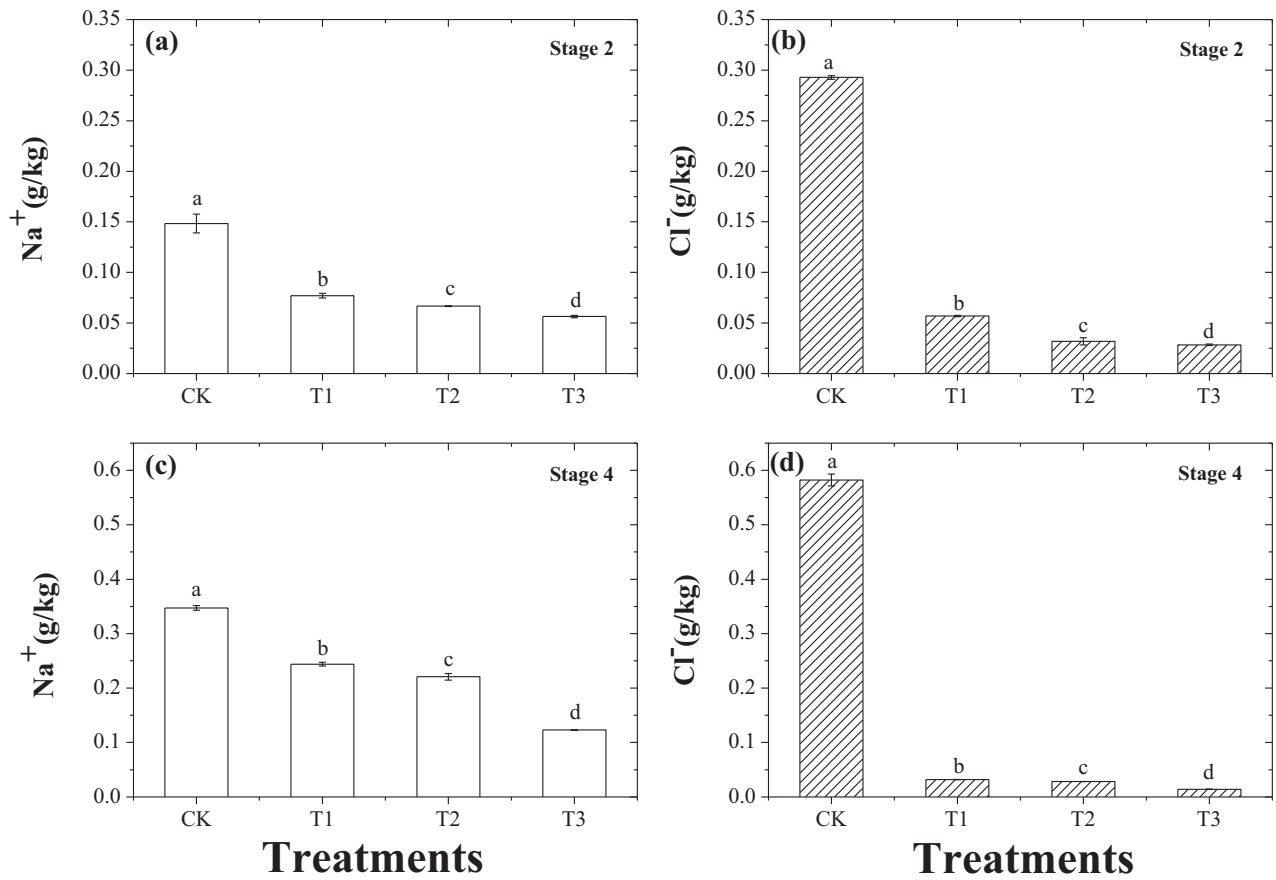
Table 3 Changes in soil organic carbon content during crop rotation

\begin{tabular}{lllll}
\hline Treatments & $\begin{array}{l}\text { Before wheat sowing } \\
\text { (benchmark) } \\
\left(\mathrm{g} \mathrm{kg}^{-1}\right)\end{array}$ & $\begin{array}{l}\text { At maize harvest } \\
\text { (stage } 4)\end{array}$ & $\begin{array}{l}\text { Carbon input from } \\
\text { biochar use }\end{array}$ & $\begin{array}{l}\text { Carbon increase from the } \\
\text { straw return }\end{array}$ \\
\hline $\mathrm{CK}^{\mathrm{a}}$ & $3.65 \pm 0.11$ & $4.87 \pm 0.49 \mathrm{c}^{\mathrm{b}}$ & $0.00 \pm 0.00$ & $1.22 \pm 0.38 \mathrm{c}$ \\
$\mathrm{T} 1$ & $3.65 \pm 0.11$ & $7.06 \pm 0.25 \mathrm{ab}$ & $0.58 \pm 0.01$ & $2.83 \pm 0.13 \mathrm{a}$ \\
$\mathrm{T} 2$ & $3.65 \pm 0.11$ & $7.37 \pm 0.45 \mathrm{ab}$ & $1.16 \pm 0.01$ & $2.56 \pm 0.33 \mathrm{a}$ \\
$\mathrm{T} 3$ & $3.65 \pm 0.11$ & $8.01 \pm 0.27 \mathrm{a}$ & $2.32 \pm 0.02$ & $2.04 \pm 0.14 \mathrm{ab}$ \\
\hline
\end{tabular}

${ }^{\mathrm{a}} \mathrm{CK}$, saline soil without biochar use; and T1-T3, saline soil with biochar amendment (at the dose of 1,2 , $4 \mathrm{~g} \mathrm{~kg}^{-1}$ )

${ }^{\mathrm{b}}$ Different lower-case letters indicate significant differences between treatments $(p<0.05$, Duncan's test)

\subsection{Salt leaching}

Figure 6 shows the contents of $\mathrm{Na}^{+}$and $\mathrm{Cl}^{-}$in soil, converted from their concentrations in soil extract at 1:5 soil: water ratio, at times close to the harvest of wheat and maize. Biochar use reduced the BD (Fig. 2) and increased Ks (Fig. 5), thus facilitating salt leaching out of the topsoil layer during irrigations and rains. Biochar use at 1,2 , to $4 \mathrm{~g} \mathrm{~kg}^{-1}$ doses favored salt leaching during spring irrigation, resulting in a reduction of $\mathrm{Na}^{+}$at wheat harvest by $48.1 \%, 55.1 \%$, and $62.0 \%$, and $\mathrm{Cl}^{-}$by $80.6 \%, 89.1 \%$, and $90.3 \%$ respectively; summer rains and autumn irrigation further helped salt leaching, lowering $\mathrm{Na}^{+}$ content at maize harvest by $29.8 \%, 36.4 \%$, and $64.6 \%$, and reducing $\mathrm{Cl}^{-}$content by $94.5 \%, 95.1 \%$, and $97.6 \%$.

\subsection{Soil organic carbon content}

Biochar increased soil organic carbon (SOC) content at the maize harvest time (Table 3). As biochar is a stable form of carbon, its addition to the soil at 1,2 , and $4 \mathrm{~g} \mathrm{~kg}^{-1}$ doses would make a direct contribution to the increase in soil carbon at $0.58,1.16$, and $2.32 \mathrm{~g} \mathrm{~kg}^{-1}$, respectively. After the deduction of carbon input from biochar, SOC contents of T1, T2, and $\mathrm{T} 3$ at maize harvest were $2.20,2.50$, and $3.24 \mathrm{~g} \mathrm{~kg}^{-1}$ higher than CK $\left(4.87 \mathrm{~g} \mathrm{~kg}^{-1}\right)$, respectively, suggesting that SOC increase was not due to biochar addition alone. Instead, straw return and straw decomposition and conversion to SOC were also the causes of carbon increase in saline soil.

\subsection{Water-stable aggregates}

Figure 7 shows that the WSA of the soil at the time close to the maize harvest. WSA increased with biochar dose from $9.4 \%$ (CK) to $11.1 \%$ (T1), $12.5 \%$ (T2), and $15.1 \%$ (T3). Biochar amendment also altered the size distribution of WSA: the smallest $(0.25-0.5 \mathrm{~mm})$ WSA increased at all biochar doses; the medium $(0.5-1 \mathrm{~mm})$ WSA only increased significantly at $4 \mathrm{~g} \mathrm{~kg}^{-1}$ dose; whereas the largest (1-2 mm) WSA was not affected by biochar addition.

\section{Discussion}

Both soil properties and biochar attributes, including the types (Obia et al. 2016; McBeath et al. 2014), particle size (Sun et al. 2018), shape (Liu et al. 2017), and the dose of biochar (Asai et al. 2009; Mukherjee and Lal 2013), determined the effectiveness of biochar use on altering soil physical properties (Burrell et al. 2016). The measurable effects, however, were often obtained by adding biochar to the soil at a large dosage, which created new problems, such as introducing salt to and causing its accumulation in soils (Saifullah et al. 2018) or becoming unaffordable to crop production (Blackwell et al.
Fig. 7 Biochar amendment improved water-stable aggregates (a, combined; b individual fractions) at stage 4. CK and T1-T3 are the same as noted in Fig. 2. Different lower-case letters at the same fraction indicate significant differences between treatments $(p<0.05$, Duncan's test)
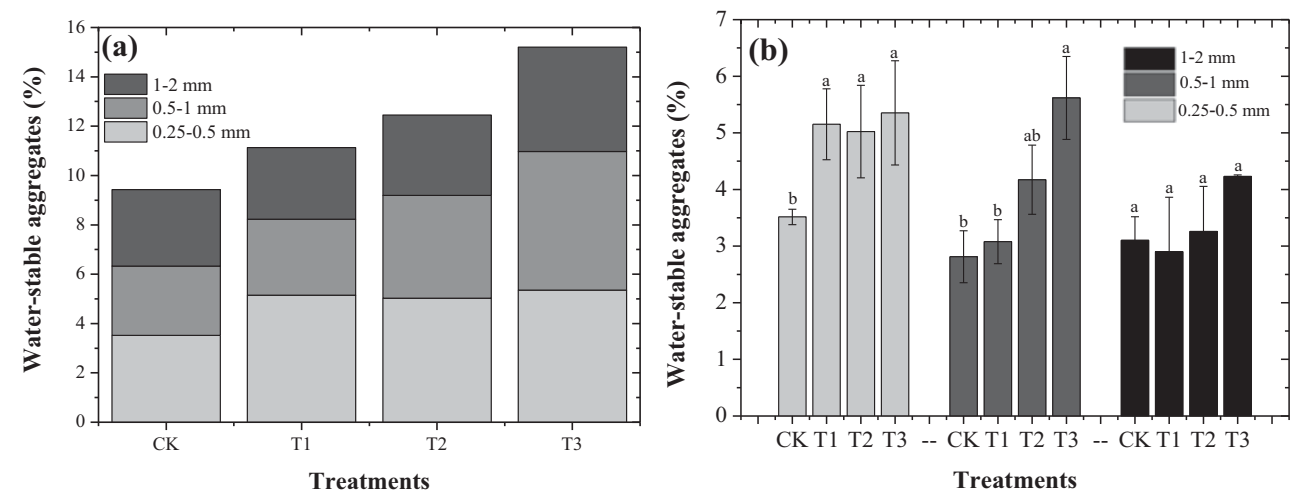
2009). Alghamdi (2018) suggested that $0.5-4 \%$ (about $7.5-$ 60 ton/ha) was an appropriate biochar dosage for improving soil porosity and aggregates. This study demonstrated that biochar at $4 \mathrm{~g} \mathrm{~kg}^{-1}$ dose, together with rotary tillage/straw returning, alleviated soil compaction, as indicated by a reduction in $\mathrm{BD}$ and an increase in CP, saturated hydraulic conductivity, and WSA. Moreover, this biochar effect on alleviating soil compaction was partially maintained during the wheatmaize cropping season. From a practical point of view, the low cost (\$24/ton) of the biochar and its ability to work at a low dosage $\left(4 \mathrm{~g} \mathrm{~kg}^{-1}\right)$ are two crucial attributes to its potential application for the remediation of salt-affected soils in the Yellow River Delta.

In terms of the factors involved in biochar alleviating soil compaction, the high specific surface area $\left(271.68 \mathrm{~m}^{2} \mathrm{~g}^{-1}\right)$, porous structure (Fig. 1), and irregular shapes of the biochar played a role. Irregular biochar particles would help soil particles to form a porous structure (Liu et al. 2017), thus increasing the FC and hydraulic conductivity (Ouyang et al. 2013; Githinji 2014). Similar views were found in the work of Major et al. (2010) and Baiamonte et al. (2019). Besides, this work proved that biochar not only produced a synergic effect with rotary tillage/ straw returning on alleviating soil compaction but also reduced the destructive effect of subsequent farming operations, such as irrigation and maize sowing, on soil structure. In other words, a combination of biochar and straw returning increased the longevity of rotary tillage on loosening soil during the crop rotation season. Furthermore, it is practically important that biochar could be added into the soil without the need for altering existing farming operations (i.e., at no extra cost).

Behind the phenomenon of biochar alleviating soil compaction is probably the role of biochar in promoting soil aggregation. Soil organic matter is an essential cementing material for the formation of soil aggregates (Yuan and Theng 2012; Li et al. 2015). This study found that biochar use increased CP and FC, in agreement with Burrell et al. (2016) and Obia et al. (2016), which in turn would improve the living environment for microbes (Zheng et al. 2017) and enhance their activities (Six et al. 2004), thus accelerating the decomposing of straw and its conversion to soil organic carbon. As shown in Table 3, both organic carbon and its increase were higher in biochar-amended treatments than in control. The observed benefits on soil aggregation from biochar use could be explained by the enhancing effect of organic cementing material produced during straw decomposition on the formation of soil aggregates (Zhao et al. 2014; Khademalrasoul et al. 2014; Xu et al. 2018), which in turn contributes to the improvement in soil structure (Blancocanqui 2017).

Alleviation of soil compaction has extra value in remediating salt-affected soil in the Yellow River Delta region. As $\mathrm{BD}$ reduced and $\mathrm{CP}$ and saturated hydraulic conductivity increased, soil aeration and water infiltration improved, which in turn helped salt leaching by irrigation and rain
(Fig. 6). Because of the shallow and salty groundwater in the Yellow River Delta, salt content in topsoil fluctuates with seasons. Salt moves up to topsoil in dry spring, moves down during spring irrigation and summer rains, and starts to accumulate in topsoil again in late autumn when the soil becomes dry. At both wheat and maize harvest times, salt contents in treatments with biochar addition were significantly lower than the control. Thus, biochar use not only created a better soil physical environment for crop growth but also reduced salt stress on crops.

The increase in WSA (Fig. 7) gives direct evidence to soil structure improvement and indicates soil fertility enhancement, and the latter was further evidenced by the increase in organic carbon content in biochar treatments (Table 3). Biochar use has dual benefits to the salt-affected soil: improving soil physical properties, and indirect increasing soil organic matter accumulation and enhancing salt leaching out of the topsoil. Thus, the biochar amendment merits further trials in the Yellow River Delta region, in conjunction with the rotary tillage and straw returning, for remediating salt-affected compact soils.

\section{Conclusions}

In wheat-maize rotation, rotary tillage with straw returning reduced the BD of a salt-affected soil from 1.48 (benchmark) to $1.27 \mathrm{~g} \mathrm{~cm}^{-3}$ and raised its saturated hydraulic conductivity $(K \mathrm{~s})$ from $0.05 \times 10^{-5}$ to $0.75 \times 10^{-5} \mathrm{~cm} \mathrm{~s}^{-1}$. This alleviation of soil compaction, however, was gradually nullified by the subsequent irrigations. Adding low-cost biochar at $4 \mathrm{~g} \mathrm{~kg}^{-1}$ dose to the soil produced a synergetic effect with rotary tillage and delayed the nullifying process. Accompanied the changes in $\mathrm{BD}$ and $K \mathrm{~s}$, salt content in topsoil was reduced, which contributed to the formation of soil organic carbon (SOC) and WSA. In other words, the increased $K$ s accelerated salt leaching out of the topsoil and enhanced the formation of SOC and WSA. This research provides evidence that a small dose $\left(4 \mathrm{~g} \mathrm{~kg}^{-1}\right)$ of biochar can be used together with rotary tillage/straw returning to lessen soil compaction problem during wheat-maize rotation in the Yellow River Delta region.

Funding information This study was funded by grants from the Chinese National Key Research and Development Program (2016YFD0200303), and Key Research and Development Program of Shandong Province (2016CYJS05A01).

\section{Compliance with ethical standards}

Conflict of interest The authors declare that they have no conflict of interest.

Research involving human participants and/or animals This article does not contain any studies with human participants or animals performed by any of the authors. 
Informed consent Not applicable. This article does not involve any individuals.

\section{References}

Ajayi AE, Holthusen D, Horn R (2016) Changes in microstructural behavior and hydraulic functions of biochar amended soils. Soil Tillage Res 155:166-175

Alghamdi AG (2018) Biochar as a potential soil additive for improving soil physical properties - a review. Arab J Geosci 11(24):755-776

Al-Wabel M, Hussain Q, Usman ARA, Ahmad M, Abduljabbar A, Sallam AS, Ok YS (2018) Impact of biochar properties on soil conditions and agricultural sustainability: a review. Land Degrad Dev 29(7):2124-2161

Asai H, Samson BK, Stephan HM, Songyikhangsuthor K, Homma K, Kiyono Y, Horie T (2009) Biochar amendment techniques for upland rice production in Northern Laos 1. Soil physical properties, leaf SPAD and grain yield. Field Crop Res 111(1):81-84

Baiamonte G, Crescimanno G, Parrino F, Pasquale CD (2019) Effect of biochar on the physical and structural properties of a desert sandy soil. Catena 175:294-303

Bao SD (2000) Soil agrochemical analysis, 3rd edn. China Agriculture Press, Beijing, pp 187-188 (in Chinese)

Blackwell P, Reithmuller G, Collins M (2009) Biochar application to soil. In: Lehmann J, Joseph S (eds) Biochar for environmental management: science and technology. Earthscan, London, pp 207-226

Blancocanqui H (2017) Biochar and soil physical properties. Soil Sci Soc Am J 81(4):687-711

Burrell LD, Zehetner F, Rampazzo N, Wimmer B, Soja G (2016) Longterm effects of biochar on soil physical properties. Geoderma 282: 96-102

Chaganti VN, Crohn DM, Šimůnek J (2015) Leaching and reclamation of a biochar and compost amended saline-sodic soil with moderate SAR reclaimed water. Agric Water Manag 158:255-265

Dong XL, Guan TY, Li GT, Li QM, Zhao XR (2016) Long-term effects of biochar amount on the content and composition of organic matter in soil aggregates under field conditions. J Soils Sediments 16(5): 1481-1497

Downie A, Crosky A, Munroe P (2009) Physical properties of biochar. In: Lehmann J, Joseph S (eds) Biochar for environmental management: science and technology. Earthscan, London, pp 13-29

Elliott ET (1986) Aggregate structure and carbon, nitrogen, and phosphorus in native and cultivated soils. Soil Sci Soc Am J 50(3):627-633

Githinji L (2014) Effect of biochar application rate on soil physical and hydraulic properties of a sandy loam. Arch Agron Soil Sci 60(4): 457-470

Herath HMSK, Camps-Arbestain M, Hedley M (2013) Effect of biochar on soil physical properties in two contrasting soils: an Alfisol and an Andisol. Geoderma 209-210:188-197

Ibrahim A, Usman ARA, Al-Wabel MI, Nadeem M, Ok YS, Al-Omran A (2016) Effects of conocarpus biochar on hydraulic properties of calcareous sandy soil: influence of particle size and application depth. Arch Agron Soil Sci 63(2):185-197

International Humic Substances Society. Acidic functional groups of IHSS samples. http://humic-substances.org/acidic-functionalgroups-of-ihss-samples/. Accessed on 20 Jun 2019

Khademalrasoul A, Naveed M, Heckrath G, Kumari KGID, Jonge LWD, Elsgaard L, Voge HJ, Iversen BV (2014) Biochar effects on soil aggregate properties under no-till maize. Soil Sci 179(6):273-283

Lehmann J, Joseph S (2009) Biochar for environmental management: an introduction. In: Lehmann J, Joseph S (eds) Biochar for environmental management: science and technology. Earthscan, London, pp 1-12
Li R, Jiang CS, Hao QJ (2015) Impact of land utilization pattern on distributing characters of labile organic carbon in soil aggregates on Jinyun Mountain. Environ Sci 36(9):3429-3437 (in Chinese, with English abstract)

Liu Z, Dugan B, Masiello CA, Barnes RT, Gallagher ME, Gonnermann HM (2016) Impacts of biochar concentration and particle size on hydraulic conductivity and DOC leaching of biochar-sand mixtures. J Hydrol 533:461-472

Liu ZL, Dugan B, Masiello CA, Gonnermann HM (2017) Biochar particle size, shape, and porosity act together to influence soil water properties. PLoS One 12(6): $\mathrm{e} 0179079$

Lu RK (1999) Analytical methods for soil and agricultural chemistry, vol 107-108. Beijing: China Agricultural Science and Technology Press, p 269 (in Chinese)

Luo XX, Liu GC, Xia Y, Chen L, Jiang ZX, Zheng H, Wang ZY (2017) Use of biochar-compost to improve properties and productivity of the degraded coastal soil in the Yellow River Delta, China. J Soils Sediments 17(3):780-789

Major J, Lehmann J, Rondon M, Goodale C (2010) Fate of soil-applied black carbon: downward migration, leaching and soil respiration. Glob Chang Biol 16:1366-1379

McBeath AV, Smernik RJ, Krull ES, Lehmann J (2014) The influence of feedstock and production temperature on biochar carbon chemistry: a solid-state 13-C NMR study. Biomass Bioenergy 60:121-129

Mukherjee A, Lal R (2013) Biochar impacts on soil physical properties and greenhouse gas emissions. Agronomy 3(2):313-339

Obia A, Mulder J, Martinsen V, Maizeelissen G, Borresen T (2016) In situ effects of biochar on aggregation, water retention and porosity in light-textured tropical soils. Soil Tillage Res 155:35-44

Omondi MO, Xia X, Nahayo A, Liu XY, Korai PK, Pan GX (2016) Quantification of biochar effects on soil hydrological properties using meta-analysis of literature data. Geoderma 274:28-34

Ouyang L, Wang F, Tang J, Zhang R (2013) Effects of biochar amendment on soil aggregates and hydraulic properties. J Soil Sci Plant Nutr 13(4):991-1002

Pietikäinen J, Kiikkilä O, Fritze H (2000) Charcoal as a habitat for microbes and its effect on the microbial community of the underlying humus. Oikos 89:231-242

Saifullah DS, Naeem A, Rengel Z, Naidu R (2018) Biochar application for the remediation of salt-affected soils: challenges and opportunities. Sci Total Environ 625:320-335

Shabangu S, Woolf D, Fisher EM, Angenent LT, Lehmann J (2014) Techno-economic assessment of biomass slow pyrolysis into different biochar and methanol concepts. Fuel 117:742-748

Shackley S, Hammond J, Gaunt J, Ibarrola R (2011) The feasibility and costs of biochar deployment in the UK. Carbon Manag 2(3):335356

Shao MA, Wang QJ, Huang MB (2006) Soil physics. Beijing: Higher Education Press, pp 37-38, 84, 142 (in Chinese)

Simon S, Jim H, John J, Rodrigo I (2011) The feasibility and costs of biochar deployment in the UK. Carbon Manag 2(3):335-356

Six J, Bossuyt H, Degryze S, Denef K (2004) A history of research on the link between (micro) aggregates, soil biota, and soil organic carbon dynamics. Soil Tillage Res 79:7-31

Sun JN, Yang RY, Li WX, Pan YH, Zheng MZ, Zhang ZH (2018) Effect of biochar amendment on water infiltration in a coastal saline soil. $\mathrm{J}$ Soils Sediments 18:3271-3279

Wei J, Tu C, Yuan GD, Wang HL, Zhang LJ, Theng BKG (2019a) Pyrolysis temperature-dependent changes in the characteristics of biochar-borne dissolved organic matter and its copper binding properties. Bull Environ Contam Toxicol 103:169-174

Wei J, Tu C, Yuan GD, Liu Y, Bi DX, Xiao L, Lu J, Theng BKG, Wang HL, Zhang LJ, Zhang XZ (2019b) Assessing the effect of pyrolysis temperature on the molecular properties and copper sorption capacity of a halophyte biochar. Environ Pollut 251:56-65 
Wei J, Tu C, Yuan GD, Zhou YQ, Wang HL, Lu J (2019c) Limited Cu (II) binding to biochar DOM: evidence from $\mathrm{C} \mathrm{K}$-edge NEXAFS and EEM-PARAFAC combined with two-dimensional correlation analysis. Sci Total Environ. https://doi.org/10.1016/j.scitotenv.2019. 134919

Xiao L, Yuan GD, Bi DX, Wei J, Shen GH (2019a) Equipment and technology of field preparation of biochars from agricultural and forest residues under aerobic conditions with water-fire coupled method. Trans Chin Soc Agric Eng 35(11):239-244 (in Chinese, with English abstract)

Xiao L, Feng LR, Yuan GD, Wei J (2019b) Low-cost field production of biochars and their properties. Environ Geochem Health:1-10. https://doi.org/10.1007/s10653-019-00458-5

Xie WJ, Wu LF, Zhang YP, Wu T, Li XP, Ouyang Z (2017) Effects of straw application on coastal saline topsoil salinity and wheat yield trend. Soil Tillage Res 169:1-6

Xu GX, Wang ZF, Gao M, Tian D, Huang R, Liu J, Li JC (2018) Effects of straw and biochar return in soil on soil aggregate and carbon sequestration. Environ Sci 39(1):355-362 (in Chinese, with English abstract)

Yuan GD, Theng BKG (2012) Clay-organic interactions in soil environments. In: Huang PM, Sumner M, Li YC (eds) Handbook of soil science: resource management and environmental impacts, 2nd edn. CRC Press, Taylor \& Francis Group, Boca Raton, pp 2-1-2-20

Zhang TT, Zeng SL, Gao Y, Ouyang ZT, Li B, Fang CM, Zhao B (2011) Assessing impact of land uses on land salinization in the Yellow River Delta, China using an integrated and spatial statistical model. Land Use Policy 28(4):857-866

Zhang T, Wang T, Liu KS, Wang LX, Zhou Y (2015) Effects of different amendments for the reclamation of coastal saline soil on soil nutrient dynamics and electrical conductivity responses. Agric Water Manag 159:115-122

Zhao X, Wang JW, Wang SQ, Xing GX (2014) Successive straw biochar application as a strategy to sequester carbon and improve fertility: a pot experiment with two rice/wheat rotations in paddy soil. Plant Soil 378(1-2):279-294

Zheng H, Wang X, Chen L, Wang Z, Xia Y, Zhang Y, Wang H, Luo X, Xing B (2017) Enhanced growth of halophyte plants in biocharamended coastal soil: roles of nutrient availability and rhizosphere microbial modulation. Plant Cell Environ 41(3):517-553

Publisher's note Springer Nature remains neutral with regard to jurisdictional claims in published maps and institutional affiliations. 